\title{
FINANCIAL MARKETS OF THE LAC REGION: CONVERGENCE AFTER THE FINANCIAL CRISIS?
}

\author{
Paula Heliodoro ${ }^{1}$ \\ Paulo Alexandre ${ }^{2}$ (i) \\ Rui Dias ${ }^{3}$
}

DOI: https://doi.org/10.31410/LIMEN.S.P.2019.45

\begin{abstract}
This paper aims to analyze whether the financial markets of the LAC Region converge towards integration in the post-global financial crisis period. The purpose of this analysis is to provide answers to two questions, namely, whether Latin American financial markets have increased their convergence as a result of the global financial crisis? If so, could portfolio diversification be called into question? The results suggest that after the 2008 financial crisis, Latin American financial markets showed a higher rate of convergence, measured by the correlation between regional market yields. In addition, we found convergence in the coefficient of movements between Latin American financial markets and the US, using dynamic linear models at the regional level. Specifically, we found consistent movements in market returns in the LAC Region, and the $S \& P 500$ index, after the financial crisis. In conclusion, this type of convergence may be a sign of the acceleration of the integration process among Latin American financial markets, which may hinder portfolio diversification.
\end{abstract}

Keywords: Financial integration, Emerging markets, Risk diversification, Dynamic linear models.

\section{INTRODUCTION}

- inancial instability is a very important factor for society, since a financial crisis or stock 1 market crash can affect, directly or indirectly, the level of economic well-being of a country's inhabitants. If a given stock market is strongly linked to the stock market of another country, the financial stability of the former depends in part on the financial stability of the latter. For this reason, a close or strong link between markets increases the levels of vulnerability to external shocks and, consequently, influences the economic conditions and welfare levels of the respective countries. The occurrence of integration between markets can have significant implications for international risk diversification (Jouini, Majdoub, and Bouhouch, 2013).

In the case of financial markets, globalisation also means transmission, comovements or contagion, notably after the breaks in the structure of international financial markets, such as the 2008 Dot-com crisis and the euro area sovereign debt crisis 2009-2011. Unlike the crises of the late 1990s, the subprime crisis originating in developed markets can be considered a truly global event that affected most financial markets and industrial sectors (Bekaert et al. 2014).

The objective of this essay is to analyze whether the financial markets of the LAC Region converge towards integration in the post-global financial crisis period. Specifically, we intend

$1 \quad$ Polytechnic Institute of Setúbal, School of Business and Administration, Esce, Campus do Instituto Politécnico de Setúbal, Estefanilha, 2914-503 Setúbal, Portugal

2 Polytechnic Institute of Setúbal, School of Business and Administration, Esce, Campus do Instituto Politécnico de Setúbal, Estefanilha, 2914-503 Setúbal, Portugal

3 Polytechnic Institute of Setúbal, School of Business and Administration, Esce, Campus do Instituto Politécnico de Setúbal, Estefanilha, 2914-503 Setúbal, Portugal 
to answer two research questions, namely whether Latin American financial markets have increased their convergence due to the global financial crisis? If so, could portfolio diversification be called into question?

We use daily data from the most relevant indexes in Latin America and cross-check them with the S\&P 500 index, in the period from 2003 to June 2012, being the sample split in two periods, 07:2003 - 12:2008 and 01:2008 - 06:2012. The results suggest the existence of synchronizations in the Latin American financial markets in relation to the U.S. market, and a higher level of comovements in the stock markets of the region after the financial crisis. This suggests a convergence of these Latin American markets, which may therefore reflect a better environment for regional financial integration.

This research adds two relevant contributions to the literature. The first contribution is related to the choice of financial markets in the LAC Region. The preference for these emerging markets is explained by the fact that they have unstable, rapidly developing economies and are therefore linked by a cultural heritage and some similar economic conditions. Additionally, these emerging markets present a financial system correlated with the financial markets, therefore, assessing the impact of the 2008 crisis on the emerging markets of the LAC Region represents a valuable opportunity to study the sensitivity of the emerging markets with the developed markets, namely that of the USA.

The second contribution is related to a direct approach, through a methodology that allows the degree of comovements between the yields of the financial markets over time to be measured. We use dynamic linear models to assess these comovements, namely the dynamic linear model: Kalman filter, Kalman smoother and Kalman forecast.

In terms of structure this test is organised into 5 sections. Section 2 presents an analysis of the State of the Art regarding articles on integration in financial markets. Section 3 provides an overview of the dynamic linear models used to verify convergence in Latin American and US financial markets. Section 4 contains the data and results. Section 5 concludes.

\section{LITERATURE REVIEW}

As part of the integration of financial markets, investors generally seek to include their assets in portfolios with low correlations in order to leverage the benefits of diversification (Dias, da Silva, and Dionísio 2019).

In the same context, Grubel (1968) and Levy and Sarnat (1970) argue that investment in international equity markets is motivated by the fact that the correlation between assets is lower than that observed in domestic assets. Therefore, the low correlation among international stock markets is the key factor of international diversification, but this correlation is dynamic over time, which affects the concept of risk reduction.

In recent decades, globalization has contributed to increase the correlation between international financial markets. Solnik, Boucrelle and Le Fur (1996) suggest that asset correlations have not increased. King, Sentana and Wadhwani (2006) have come up with similar results, examining the links between international markets. Chen, Firth and Meng Rui (2002), Sakthivel, Bodkhe and Kamaiah (2012) and Weber (2013) show convergence between assets and stock markets in different regions. 
Abu-Alkheil et al. (2016) and Alotaibi and Mishra (2016) analyzed the level of financial integration and tested the assumptions of portfolio risk diversification. Abu-Alkheil et al. (2016) analyzed 32 Islamic stock markets and 32 conventional stock indices in the period 2002-2014. The results of the econometric tests reveal the absence of financial integration among the 31 Islamic indices, except for Pakistan. In summary, the authors suggest that the absence of financial integration among the 31 pairs of Islamic indices creates opportunities for investors to pursue risk diversification strategies. In a complementary manner, Alotaibi and Mishra (2016) examined the level of financial integration of the Persian Gulf markets in the period 2002-2013. The results propose the existence of financial integration in these financial markets, except for the Saudi Arabian market. Given these results, the hypothesis of diversification is not consistent for most of these regional markets.

\section{METHODOLOGY}

In this study, the first step in econometric analysis is to evaluate the time series stationarity. This analysis becomes essential since such characteristics are fundamental for the data generator process modelling (Lütkepohl and Krätzig 2004).

The Augmented Dickey-Fuller test (Dickey and Fuller 1981) postulates that the null hypothesis is non-stationary or integrated of order $d(d>0)$, I (1), against the alternative hypothesis of stationarity (Said and Dickey 1984) To validate the ADF test, we use the KPSS test (Kwiatkowski et al. 1992) where the hypotheses presented are contrary to the ADF test, i.e. $\mathrm{H}_{0}$ postulates that the series is I (0) against the alternative that the series are I (1) (Noman and Rahman 2010).

Our analysis is based on daily annual returns from July 1, 2003 to June 25, 2012. We use data from the S\&P index and the most important stock market indices in Latin America. These markets are Argentina, Brazil, Chile, Colombia, Mexico, and Peru.

We implement a Dynamic Linear Model (Campagnoli et al. 2009; Campagnoli, Petrone, and Petris 2009; Petris 2010) to check the convergence of the sensitivity of the Latin American stock markets with the US stock market. We specify the following Gaussian linear state space model:

$$
R_{L A, t}=\left[\begin{array}{ll}
1 & R_{U S, t}
\end{array}\right]\left[\begin{array}{l}
\beta_{1, t} \\
\beta_{2, t}
\end{array}\right]+v_{t}=F_{t} \beta_{t}+v_{t}
$$

and

$$
\left[\begin{array}{l}
\beta_{1, t} \\
\beta_{2, t}
\end{array}\right]=\left[\begin{array}{l}
\beta_{1, t-1} \\
\beta_{2, t-1}
\end{array}\right]+\left[\begin{array}{l}
w_{1, t} \\
w_{2, t}
\end{array}\right]=\beta_{t-1}+w_{t}
$$

Where $R_{L A, t}$ is the return of each of the six Latin American stock markets (Argentina, Brazil, Chile, Colombia, Mexico and Peru) and $R_{U S, t}$ is the return of the US market (S\&P 500).

Kalman filter: Given the dynamic linear model defined by equation (1) and (2) and the initial condition, let $\beta_{t-1} \mid R_{L A, 1: t-1} \sim N_{2}\left(m_{t-1}, C_{t-1}\right)$ the folowing statements hold:

The one step ahead predictive distribution of $\beta_{t-1}$ given $R_{L A, 1: t-1}$ is Gaussian, with parameters

$$
a_{t}=E\left(\beta_{t} \mid R_{L A, 1: t-1}\right)=m_{t-1}
$$


and

$$
\Omega_{t}=\operatorname{Var}\left(\beta_{t} \mid R_{L A, 1: T-1}\right)=C_{t-1}+W
$$

The one step ahead predictive distribution of $R_{L A, t}$ given $R_{L A, 1: t-1}$ is Gaussian, with parameters

$$
f_{t}=E\left(R_{L A, t} \mid R_{L A, 1: t-1}\right)=F_{t} a_{t}
$$

and

$$
Q_{t}=\operatorname{Var}\left(R_{L A, t} \mid R_{L A, 1: t-1}\right)=F_{t} \Omega_{t} F_{t}^{\prime}+\sigma_{v}^{2}
$$

The filtering distribution of $\beta_{t}$ given $R_{L A, t}$ is Gaussian, with parameters

$$
m_{t}=E\left(\beta_{t} \mid R_{L A, 1: t}\right)=a_{t}+\Omega_{t} F_{t}^{\prime} Q_{t}^{-1} e_{t}
$$

and

$$
C_{t}=\operatorname{Var}\left(\beta_{t} \mid R_{L A, 1: t}\right)=\Omega_{t}-\Omega_{t} F_{t}^{\prime} Q_{t}^{-1} F_{t} \Omega_{t}
$$

Where $e_{t}=R_{L A, t}-f_{t}$ is the forecast error.

Kalman smoother: Given the dynamic linear model defined by equation (1) and (2), and the initial condition, if $\beta_{t+1} \mid R_{L A, 1: T} \sim N_{2}\left(S_{t+1} ; S_{t+1}\right)$, then $\beta_{t} \mid R_{L A, 1: T} \sim N_{2}\left(s_{t} ; S_{t}\right)$, where

$$
s_{t}=m_{t}+C_{t} \Omega_{t+1}^{-1}\left(s_{t+1}-a_{t+1}\right)
$$

and

$$
S_{t}=C_{t}-C_{t} \Omega_{t+1}^{-1}\left(\Omega_{t+1}-S_{t+1}\right) \Omega_{t+1}^{-1} C_{t}
$$

Kalman forecast: Given the dynamic linear model defined by equation (1) and (2), and the initial condition, let $a_{t}(0)=m_{t}$ and $\Omega_{t}(0)=C_{t}$. Then, for $k \geq 1$, the following statements hold.

The distribution of $\beta_{t+k}$ given $R_{L A, 1: t}$ is Gaussian, with

$$
a_{t}(k)=a_{t, k-1}
$$

and

$$
\Omega_{t}(k)=\Omega_{t, k-1}+W
$$

The distribution of given Gaussian, with

$$
f_{t}(k)=f_{t+k} a_{t}(k)
$$

and

$$
Q_{t}(k)=F_{t+k} \Omega_{t}(k) F_{t+k}^{\prime}+\sigma_{v}^{2}
$$




\section{RESULTS}

The unit root tests ADP, PP and KPSS show that the time series are integrated of order (I), that is, they are stationary in first differences. In addition, we conducted cointegration tests that show non-significant results in the period from 2003 to 2012.

Figure 1 shows the evolution of the price indices, in first annual differences, of the seven markets under analysis. The price indices represented clearly reveal a period of great turbulence (2007-2009), and a second more tranquil period.

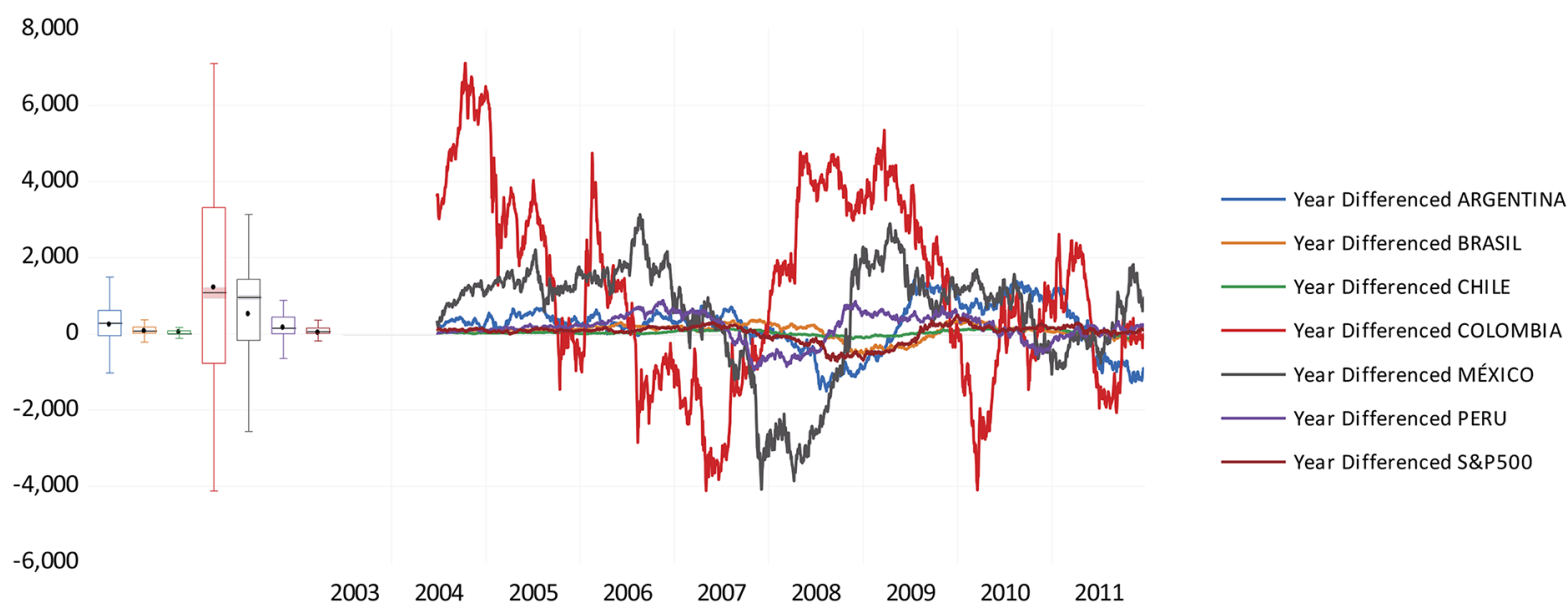

Figure 1. Evolution, in first differences, of the 7 stock market indices, in the period 15/07/2003 to 25/06/2012.

Source: Thomson Reuters.

Figure 2 shows the evolution of Latin American stock market yields, and the S\&P 500 index. In all the yield series there is a relatively high dispersion around the average, as well as a relatively synchronised behaviour between the data series. The graphical analysis shows a high volatility, especially in the 2007-2009 period.

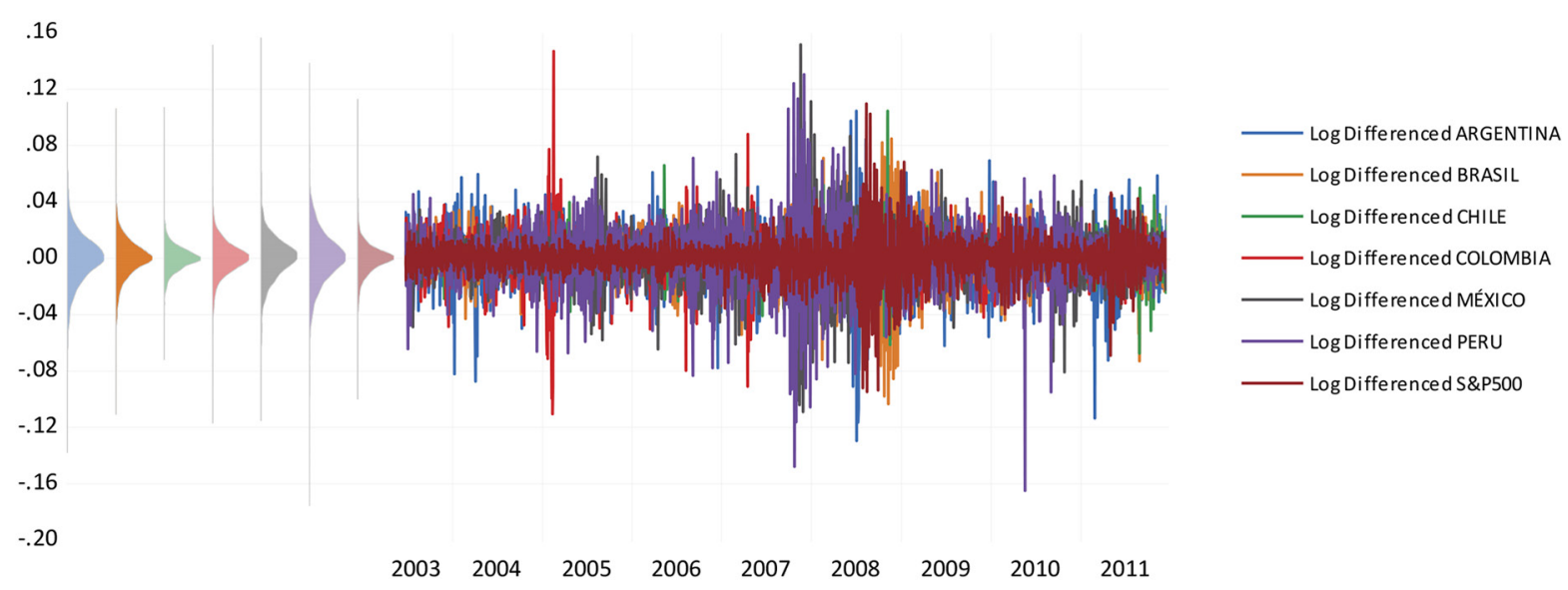

Figure 2. Evolution, in returns, of the 7 stock market indices, in the period 15/07/2003 to 25/06/2012.

Source: Thomson Reuters. 
The correlation coefficients between Argentina, Brazil, Chile, Colombia, Mexico, Peru and the S\&P index for the period 2003-2012 are significant, 0.76, 0.70, 0.81, 0.62, 0.88 and 0.69, respectively. However, when we compare the correlation coefficients before and after the 2008 financial crisis, we detect significant deviations.

Specifically, the correlation coefficient for each country in the period from 2008 to 2012 is higher than the coefficients in the period from 2003 to 2007. We carried out William's test (Steiger, 1980), and the results suggest that the correlations are not equal in both periods, except for Brazil. In addition, when considering separately the periods before and after the crisis, the results show that the period before the crisis presents a lower average level of correlation in the LAC Region markets, and the US market (0.47), with a very significant profitability (56.37\%), and a lower volatility (35.03\%). However, in the post-crisis period it has a higher correlation between the Latin American markets, and the S\&P index (0.83), resulting in lower returns (13.74\%) and greater volatility (43.23\%).

After the crisis, the correlations between the region's stock exchanges are very significant when compared to the previous period. For example, the correlation coefficient between Colombia and Peru in the period prior to the 2008 crisis is (-0.64) rising to 0.87 in the post-crisis period. Argentina and Peru also show significant changes before the crisis $(-0.17)$ and in the post-crisis period 0.91. Mexico and Argentina also show significant values before the crisis $(-0.11)$, in the post-crisis period 0.91 . One explanation for this phenomenon may have been the creation of the Latin American Integrated Market (MILA).

We carried out a descriptive analysis of the smoother Kalman filter associated with $\beta$ _(2.t), in the period from January 2008 to June 2012 for each model and observed that the Brazilian market presents a higher sensitivity with the US market, with an average of 1.91, but also a higher volatility, with a standard deviation of 0.69 . On the other hand, Chile presents a lower volatility, with a standard deviation of 0.22 . In addition, the markets of Colombia, Peru (0.72) and Chile (0.79) show a lower sensitivity with the US index.

The results resulting from the standard deviation methodology of $\operatorname{Kalman}$ smoother for $\beta \_(2, t)$, in both periods (07:2003 - 12:2007 and 01:2008 - 06:2012), show significant decreases in volatility, namely between Latin American markets with the US index. The Peru market shows a standard deviation of 0.32 in the first period, and this volatility drops to 0.20 in the second period. Colombia had the most significant drop in volatility, with a standard deviation of 0.78 in the first period and 0.13 in the post-crisis period.

The results from the mean of Kalman smoother for $\beta_{-}$(2.t) methodology, in both periods (07:2003 - 12:2007 and 01:2008 - 06:2012), clearly show a significant convergence in the post-crisis period. For example, the country with the highest average $\beta \_(2, t)$, in the period 2003-2007 is Brazil, with 2.25 , while Peru had the lowest average $\beta \_(2, t)$, with 0.56 . In the second period, 2008-2012, $\beta$ (2.T), of Brazil decreased 0.68 points, while Peru had an increase of 0.33 . These changes mean that the average of $\beta_{-}$(2.t), Peru and Brazil in the second period is 0.89 and 1.57 , respectively.

A possible explanation for these results is related to the existence of increased synchronization among international financial markets. Thus, the events that occur in some markets are transmitted to others in different regions of the world. Several studies have found evidence of movements and transmission of volatility between Latin American financial markets and the US market, namely the authors Melo and Rincón (2013), Weber (2013), Gamba-Santamaria et al. (2017). 


\section{CONCLUSION}

The main conclusions show that the financial crisis in the US has caused synchronization among the financial markets of the LAC Region. Additionally, we found evidence of a very significant level of correlations between Latin American markets after the 2008 financial crisis. In addition, we found that the sensitivity of the Latin American markets to the US market presents consistent movements, which leads to a significant synchronization of the region with the US market. This type of synchronized reaction may accelerate the integration process between the financial markets of the LAC Region.

In conclusion, during the period of the 2009-2011 Eurozone sovereign debt crisis, these regional markets showed a positive trend in the Latin American and US markets, i.e. there were no significant moves from the European markets to the Latin American regional markets. In addition, the results of the dynamic models showed significant convergence, i.e. these markets tend towards integration, in the post sub-prime period, which may hamper portfolio diversification in these regional markets.

Regarding suggestions for future studies, we suggest a better understanding of the factors driving increasing convergence and correlation between the financial markets of the LAC region and the US market.

\section{REFERENCES}

Abu-Alkheil, Ahmad, Walayet A. Khan, Bhavik Parikh, and Sunil K. Mohanty. 2016. Quarterly Review of Economics and Finance Dynamic Co-Integration and Portfolio Diversification of Islamic and Conventional Indices: Global Evidence. Board of Trustees of the University of Illinois. http://dx.doi.org/10.1016/j.qref.2017.02.005.

Allen, Franklin, Xian Gu, and Oskar Kowalewski. 2012. "Financial Crisis, Structure and Reform." Journal of Banking and Finance.

Alotaibi, Abdullah R., and Anil V. Mishra. 2016. "Time Varying International Financial Integration for GCC Stock Markets." The Quarterly Review of Economics and Finance: 1-13. http://www.sciencedirect.com/science/article/pii/S1062976916000272.

Bekaert, Geert, Michael Ehrmann, Marcel Fratzscher, and Arnaud Mehl. 2014. "The Global Crisis and Equity Market Contagion." Journal of Finance.

Campagnoli, Patrizia et al. 2009. "Dynamic Linear Models.” In Dynamic Linear Models with R.

Campagnoli, Patrizia, Sonia Petrone, and Giovanni Petris. 2009. Dynamic Linear Models with R Dynamic Linear Models with R.

Chen, Gong-meng, Michael Firth, and Oliver Meng Rui. 2002. "Stock Market Linkages: Evidence from Latin America.” Journal of Banking \& Finance 26(6): 1113-41. http://linkinghub.elsevier.com/retrieve/pii/S0378426601001601.

Dias, Rui, Jacinto Vidigal da Silva, and Andreia Dionísio. 2019. "Financial Markets of the LAC Region: Does the Crisis Influence the Financial Integration?” International Review of Financial Analysis.

https://www.sciencedirect.com/science/article/pii/S1057521918305829 (April 8, 2019).

Dickey, David, and Wayne Fuller. 1981. "Likelihood Ratio Statistics for Autoregressive Time Series with a Unit Root." Econometrica 49(4): 1057-72.

Gamba-Santamaria, Santiago, Jose Eduardo Gomez-Gonzalez, Jorge Luis Hurtado-Guarin, and Luis Fernando Melo-Velandia. 2017. "Stock Market Volatility Spillovers: Evidence 
for Latin America." Finance Research Letters 20: 207-16. http://dx.doi.org/10.1016/j. frl.2016.10.001.

Grubel, Herbert G. 1968. "Internationally Diversified Portfolios: Welfare Gains and Capital Flows." The American Economic Review.

Jouini, Jamel, Jihed Majdoub, and Ines Ben Bouhouch. 2013. Emerging Markets and the Global Economy: A Handbook Equity Market Comovements Among Selected Emerging Countries from Long- and Short-Run Perspectives. Elsevier Inc. http://dx.doi.org/10.1016/B9780-12-411549-1.00027-2.

King, Mervyn, Enrique Sentana, and Sushil Wadhwani. 2006. "Volatility and Links between National Stock Markets." Econometrica.

Kwiatkowski, Denis, Peter C. B. Phillips, Peter Schmidt, and Yongcheol Shinb. 1992. "Testing the Null Hypothesis of Stationary against the Alternative of a Unit Root." Journal of econometrics 54(1): 159-78.

Levy, Haim, and Marshall Sarnat. 1970. "International Diversification of Investment Portfolios." American Economic Review.

Lütkepohl, Helmut, and Markus Krätzig. 2004. Applied Time Series Econometrics Applied Time Series Econometrics.

Melo, Luis Fernando, and Hernán Rincón. 2013. "Choques Externos y Precios de Los Activos En Latinoamérica Antes y Después de La Quiebra de Lehman Brothers.” Ensayos Sobre Politica Economica.

Noman, Abdullah M, and M Zillur Rahman. 2010. "Stationarity of South Asian Real Exchange Rates Under Exponential Star (ESTAR) Framework." The Journal of Developing Areas 43(2): 41-50. http://muse.jhu.edu/journals/journal_of_developing_areas/v043/43.2.noman. html\%5Cnhttp://muse.jhu.edu/journals/journal_of_developing_areas/v043/43.2.noman.pdf.

Petris, Giovanni. 2010. “An R Package for Dynamic Linear Models.” Journal of Statistical Software.

Said, Said E., and David A. Dickey. 1984. "Testing for Unit Roots in Autoregressive Moving Average Models of Unknown Order.” Biometrika 71(3): 599-607.

Sakthivel, P., Naresh Bodkhe, and B. Kamaiah. 2012. "Correlation and Volatility Transmission across International Stock Markets: A Bivariate GARCH Analysis.” International Journal of Economics and Finance.

Solnik, Bruno, Cyril Boucrelle, and Yann Le Fur. 1996. "International Market Correlation and Volatility." Financial Analysts Journal.

Steiger, James H. 1980. “Tests for Comparing Elements of a Correlation Matrix.” Psychological Bulletin.

Weber, Enzo. 2013. "Simultaneous Stochastic Volatility Transmission across American Equity Markets." Quarterly Review of Economics and Finance. 